Vol. LXVI 2015

\title{
THE OBJECTIVE IDENTIFICATION OF HAZARDS - THE ESSENTIAL CONDITION TO A REAL EVALUATION OF OCCUPATIONAL INJURIES AND ILLNESSES’ RISKS
}

\author{
Mihai-Adrian BERNEVIG-SAVA \\ Faculty of Material Science and Engineering /Material engineering department and industrial safety, Technical \\ University „Gheorghe Asachi” from Iași, Iași, Romania, e-mail mihaibernevig@gmail.com
}

\author{
Nicoleta Monica LOHAN
}

Faculty of Material Science and Engineering / Material engineering department and industrial safety, Technical University „Gheorghe Asachi” from Iași, Iași, Romania

\section{Constantin BACIU}

Faculty of Material Science and Engineering / Material engineering department and industrial safety, Technical University „Gheorghe Asachi” from Iași, Iași, Romania

Costică BEJINARIU

Faculty of Material Science and Engineering / Material engineering department and industrial safety, Technical University „Gheorghe Asachi” from Iași, Iași, Romania

\begin{abstract}
The paper discuss about the process of hazards identification in order to evaluate occupational injuries and illnesses' risks, a problem that has been debated in many publications by different specialists, but which has not been concretized as a framed step in a defined context, without permiting the evaluator or the evaluation team to introduce the subjectivism as an influence factor.
\end{abstract}

Key words: identification, hazard, evaluation

\section{Introduction}

As it is defined in the Romanian Dictionary, „hazard is a situation, an event which puts or could put in danger the existence and the integrity of someone or something”.

Hazard, in a definition that can be found on the European Agency for Safety and Health at Workplace site, can be any potential source of harm - material, equipment's, methods or work practice. And we can add, of a specific gravity.

The hazard of occupational injuries and illnesses, defined in the Dictionary - Safety and Health at Workplace elaborated by the National Institute of Research- Development for Work Protection, is a source of a possible harm of the health of a work process' executant. Between the occupational injuries and illnesses' risk and the hazard of occupational injuries and illnesses there is an intrinsically connection: risk is a potential hazard.

The occupational injuries and illnesses' risk is a combination between the possibility and the gravity of a possible harm of the health in a dangerous situation; potential hazard of the occupational injuries and illnesses.

A risk is the probability, small or big, that a person is being harmed as a result of hazard, with foreseeable consequences when being analyzed, evaluated.

However, hazard can be defined as a notion represented by the fact condition which, through fenomens associations which cannot be entirely controlled, generate the making or the manifestation, in a period of time, of harmful effects, which can be rhymed through different measures, at one or many elements from work's system.

The making of a paper which evaluates the occupational injuries and illnesses' risk which contain: "- identification of hazards and evaluation of risks for each component of the work's system, (executant, work duty, ways of working / working equipment and work environment on working places/ 
workstations) and setting the technical, organizational and sanitary specific measures in conformity with the foresight of the law nr. 319 from $14^{\text {th }}$ of July 2006 of safety and health at workplace, art.7, align, 4, letter a, in order to apply the imposed measures from align. 4, let. B, c, d, e, align. 1, 2, 3 and the HG 1425 from $11^{\text {th }}$ October 2006 modified with The Decision $\mathrm{nr}$ 955/2010, art. 15, align. 1, pct. 2” and requires a stage of hazards' identification.

This stage can be considered the most important part of an evaluation process of risks because it allows to highlight the work's security lacunas for the analyzed system as well as the generating or possible generating factors of injuries with a bigger or smaller gravity. An objective analyze allows to adopt some remedies that may lead to avoiding some events even if they are occupational injuries or illnesses, but the same stage could highlight things that are made reflexively, from experience or documentation and proves that many of the possible injuries' causes are taking into account and diminishing as manifestation probability through operations of maintenance, daily evidences, old and experienced workers.

\section{2. between reality and ,imagination”}

The concept of „risk” can be defined based on the relationship between the possibility of the event's manifestation and the gravity of its manifestation's consequences. Having as mark the estimation of the maximum gravity of the manifestation's consequences, an optimistic person can trifle the maximum effects and a pessimistic person can lead to the maximum-death effect and possible manifestation of hazard.

For the probability of manifestations may still exist a history within some old companies, but we see ourselves in a situation in which we have to presume, to estimate and rarely there are making correlations with the values into industrial staples, when it comes to recently established unities.

However, the more the gravity of the consequences is higher, factual when we discuss about a history or casuistry or supposed in maximum pessimism case, the more it can be said that an event is more dangerous. Consequently, an identification of hazards can call in question even if this process has been carried on using an identification list or if we discuss about the existence of an evaluation committee which has more members. The explanation of this affirmation can be made through the possibility of implication of a factors plurality or just a disruptive one, such as:

- The existence of people with strong personality, who can influence, justified or not, the other members of the committee.

- the technical concepts which they own and the knowledge about how the equipment's work, the evolution of some flaws, the way of manifestation

- knowledge about chemical reactivity of some substances, their behavior in different conditions, such as gases, particles appearance or vapors disengagement in some processes, including fire;

- $\quad$ how can evolve an affection, from medical point of view;

- limited language with the possibility of deliverance of the risk's manifestation in an artificial way, with a single word or copied from the identification list;

- Combination of more predictive factors "if" which it is added to the distrust, pessimism, negative social experiences.

These elements which influence the whole process of identification the hazards with purpose of evaluation the occupational injuries and illnesses' risks are completed by "the necessity" of Appling some complicated evaluation methods, which in some cases of small units, authorized persons, individual industry they cannot be applied very well, due to the concepts of massive explanations with purpose of financial justification. This aspect is completed by a deficiency of some basic knowledge in Safety and Health at Workplace domain, which is not associated with Work Protection but with safety of the goods knowledge.

\section{Necessities and priorities}

Even if the legislative system in Safety and Health at Workplace domain has entered into force, mostly, in year 2006 it has been placed in a second plan due to the factors of economic instability which have focused the majority's attention to professional reorientation directions, emigration, and fast incomings with minimal infestations. To these factors it has been added a void created by the concept of self-instruction and the content of it as well as the dispersed factors in normative documents from sort of different domains or different legal forecasts. For example:

- the definition of working at height can be find in Decision nr.355 from $11^{\text {th }}$ of April 2007 for supervision of workers' health, section 5 , file 123 ; 
- The definition of workplace can be find in Law nr. 319/2006 of Safety and Health at Workplace, art.5, let. K: workplace - the place for workstations, situated inside the enterprise's building and/or unity, including any other place of enterprise's area and/or unity to which the worker has access to perform an activity; and the definition of workstation in Decision nr. 1028 from $9^{\text {th }}$ of August 2006 for minimum requests of safety and health at workplace, referring to usage of equipment's provided with display at art. 4 , let. B being an assembly which contain an equipment provided with display, keyboard, or a device to fill in the dates and/or a program which can settle down the interface operator/machine, optional, periphery accessories, including the floppy disk and/or the optic unity, phone, modem, printer, documents support, chair, table or working surface and the working environment.

Even if we can consider the workstation different if we take into consideration the specified elements in Decision nr. 1028/2006, to systematize the workplaces, that does not mean that the hole content of legal framework is noticeably simplified and handy to the employer who has duties in Safety and Health at workplace domain and has the right qualities given by the 40 hours course, but he does not have technical knowledge. In this category can be included the activities that make an exception from the content of Annex nr. 5 from Standard Methodology of Appling the forecasts of Law nr 319/2006 of Safety and Health at Workplace, approved by the Decision nr 1425/2006, including the unities that have at most forty nine (according to art.17, pct. (1) from the Decision nr.1425/2006) in which the employer can perform an activity effectively and with regularity. The same legal forecast discuss in art.17, pct. (1), letter .B. the fact that "the identified risks cannot generate occupational injuries or illnesses that have serious consequences, irreversible, that is death or invalidity" in other words there will be no areas with raised and specific risk.

These aspects can be seen as if they would help the employer, by realizing the fact that there is necessary to take some measures, no matter what activity is performed or the reason „we do not have risks” or „I have never heard about anyone dying from working at...” and integrating the concept of safe investment in the safety and health of workers, but at the same time it has to face a challenge, that is to identify the risks. However, as we have seen, the forerunner step before the identification and evaluation of the risks it consists of identification the existent hazards in the analyzed work system. Thus, it will reach to the point where subjectivism and the employer interest may lead to a situation in which hazards are not highlighted or the gravity of the effects are reduced and in this way they should not invest in audit activities or evaluation with experienced third parties, who have competences for that matter. This possible attitude can put in danger the workers' safety by not knowing them.

\section{Conclusions}

Even if the annex nr. 6 from Methodology of enforcement the Safety and Health at Workplace Law nr. 319/2006 impose clearly that the course support intended for preparing programs in safety and health at workplace domain for employer and, also, for the employers' attorney with specific responsibilities in safety and health at workplace for employers domain to contain concepts about general risks and how to prevent them and also concepts about specific risks and how to prevent them in the appropriate zone for the activity of the enterprise and/or the unity this cannot customize „on the scene” the real working conditions and to present them in the context of the minimum requests of work safety requested by the Romanian legal framework harmonized with the European one in order to practically apply the safety and health at workplace principles.

If we take into consideration the fact that the Safety and Health at Workplace European Agency offers to employers or to those who are interested a series of instruments to evaluate the risks and surveillance lists, which have the purpose to sustain the small enterprises to perform evacuation of the risks and which help to identify the major hazards from the workplace, but cannot identify the hazards, major or minor, when it comes to the peculiarity of the work environment , the legal request especially the biological risks, children and youths, pregnant women, etc..

The fact that there are instruments to identify the hazards, does not mean that they can be improved by someone from outside of the specific unit, without direct contact with the process of the work and with the entirely analyzed system to customize them. If any person, unity, organism of some instruments (lists, files, soft) offers without having cumulative- the necessary experience both in identification/evaluation the risks and performing the activities in the safety and health at workplace domain, adequate knowledge about the manifestation of some technological processes, without solid knowledge about the minimum legal requests to be put in conformity with those and especially without 
involving the workers or their attorney, the whole process of identification the hazards in order to fulfill the paper of evaluation of occupational injuries and illnesses’ risks, is compromised.

\section{References}

- The Law nr. 319 from $14^{\text {th }}$ of July 2006 of safety and health at workplace enforced by the Decree nr. 956 from 13th of July 2006, Published in The Official Monitor number 646 since 26th of July 2006.

- Norms from 11th of October 2006 to apply the Laws of safety and health at workplace forecasts nr. 319/2006 approved by The Decision nr. 1425 from 11th of October 2006, Published in The Official Monitor number 882 since 30th of October 2006.

- http://www.dexonline.ro

- Urdă, Ion, Dr. irig., «Damage industry - management of the fault condition », Publisher AGIR, (2006)

- Pece, Ștefan, Dr. ing., Dăscălescu, Aurelia, Ec., Iorga, Ionel, Dr. ing., Darabont, Alexandru, Prof.univ.dr.ing., Costescu, Mihai, Dr.ing., Mereț, Nicolae, Dr.ing., Olteanu, Constantin, Ing., Tudorică, Constantin, Ing, DEX Safety and Health at Workplace - Dictionary, National Institute of Research and Development for Work Protection, Publisher GENICOD, Bucharest, (2001) 